\title{
Learning Society in Unesco Kien Giang Biosphere Reserve, Kien Giang Province, Mekong Delta, Vietnam
}

\author{
Nguyen Hoang Tri (corresponding author) \\ Chairman, Vietnam MAB National Committee (MAB Vietnam) \\ hoangtri1951@gmail.com
}

\section{Nguyen Xuan Niem \\ Vice Director, Department of Science and Technology of Kien Giang Province. Member, Management Board for Kien Giang World Biosphere Reserve}

\section{Ly Minh Tai}

Management Board for Kien Giang World Biosphere Reserve

\author{
Tran Duc Tuan \\ Director, Center for Education Research and Support for \\ Sustainable Development (CEREPROD)
}

\section{Pham Van Giau}

Management Board for Kien Giang World Biosphere Reserve

$\mathrm{Vu}$ Thuc Hien

Publication Information:

Received 7 April 2019, Accepted 2 May 2019, Available online 1 June 2019

DOI: 10.21463/jmic.2019.08.1.02

\begin{abstract}
This article presents the results of a study on the applicability of a learning society model through transformative learning activities for sustainable development in the context of climate change in the UNESCO Biosphere Reserve of Kien Giang, Mekong River Delta, Vietnam. With the use of a new approach to socio-ecology research and participatory learning, the study shows the rationality of using functional zones of the biosphere reserves as large bio-geographic sites, which facilitate the connection of spaces for thinking, cooperation, exchange and realization of creative ideas as well as preservation of traditional culture of local people in coastal and island region. Diverse learning methods as well as applicability of participatory learning in the community help to develop a strategy to improve people's adaptability to changes in nature and socio-economic development in the context of local climate change. The report also analyzes lessons learned in applying new approaches to the development of new ideas and initiatives in the present context of Vietnam.
\end{abstract}

\section{Keywords}

Biosphere Reserve, learning society, transformative learning, participatory learning 


\section{Introduction}

\section{Concept of Biosphere Reserve and Kien Giang Biosphere Reserve}

A Biosphere Reserve (BR) is a geographic zone representative of the mainland, coastal areas, and islands, which is documented by a nation to meet the seven UNESCO/MAB criteria to be included into the UNESCO World Network of Biosphere Reserves (WNBR). This would be a model of sustainable development at a local, national and international level (UNESCO / MAB, 2015, 2016).

Kien Giang Biosphere Reserve (KGBR), which was designated by UNESCO in 2015, is one of the nine BRs in Vietnam, belonging to the world Network of 686 BRs from 122 countries; all the BRs are zoned with three functions of conservation, development and logistic support and meet the seven criteria of UNESCO/MAB. KGBR is on a total area of 1,188,104ha, with over 400,000 people. The three core areas (36,935ha) of KGWBR are Phu Quoc National Park, U Minh Thuong National Park and Hon Chong Nature Reserve. A large buffer zone of 172,578ha surrounds and connects all the three core areas. The transitional zone outside covers an area of 978,591ha. As seen in Fig. 1, this vast space accommodates most of the ecosystems and biodiversity of Kien Giang in particular, and the Mekong Delta in general. Socio-economic and cultural activities in here are also characteristic of this region (Committee, 2006, PC, 2014).

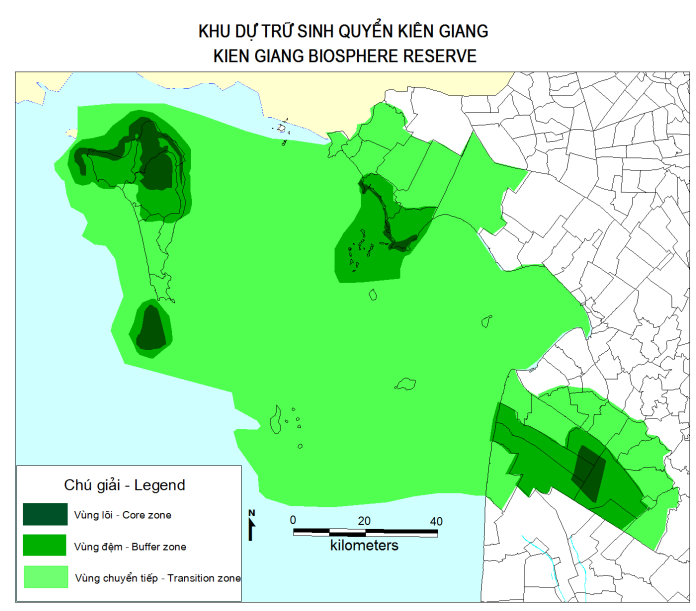

Fig 1. Zonation map of Kien Giang WBR - A space for T-learning application

\section{Learning society, transformation learning and participatory learning}

A 'learning society' is defined as an:

educational philosophy advocated by the OECD and UNESCO that positions education as the key to a nation's economic development, and holds that education should extend beyond formal learning (based in traditional 
educational institutions - schools, universities etc.) into informal learning centers to support a knowledge economy (known as a "world education culture"). (Wikipedia)

It is identified through lifelong learning activities, not dependent on learning location/place.

The core of a learning society is the transformative learning process (T-learning) and the process of Transgressive learning. T-learning is the social psychosocial processes of consciousness and emotion, creating social changes; sometimes, these are changes in perceptions and behavior/acting. This learning process also generates collective critical thinking of practical value for sustainable development (Lotz-Sisitka et al., 2016; Wals, 2009). In 2015, the International Council for Social Sciences developed a research program on the transition to sustainable development; the program has sought social solutions to the challenges of climate change and the environment. At the same time, the program has helped create a transformative knowledge network that has connected scientists, civil society, managers, businesses, and various social sectors (Cranton, 2016; Edward W Taylor, 2012; McKeown, 2002).

Learning is seen as an important driving force of change towards sustainable development, but there are still very few transformative learning models that bring about this change in practice. Participatory learning is a learning process in which everyone in the community can participate in as a teacher or learner; these roles can be interchanged, depending on the practical needs. Taking on the role of a teacher, a farmer can explain his or her success; but he is also willing to be a trainee in other subjects. Similarity can be seen in the relationship between students, families and societies (Ha, Bosch, \& Nguyen, 2016; Lotz-Sisitka et al., 2016).

This study has started in 2017 and will be ended in 2018 with research hypothesis: The research findings should answer the research questions: Can T-learning be applied in Kien Giang BR? What are factors that assure the successful application of this process locally? and Why?

This has been conducted in Kien Giang BR, Kien Giang Province located in Mekong Delta, South of Vietnam. It is one of two study sites in Vietnam (Kien Giang BR and Can Tho city), representative for the Mekong River, Vietnam. This is also one of the nine global study sites in seven countries with in Transformative Knowledge Network Grant no: 160314115141 lead by Rhodes University, South Africa.

\section{Study Approach And Methods}

\section{Socio-ecology approach to structural and functional analysis of BRs}

The ultimate goal of building and managing BRs is to create harmony between people and nature through the implementation of the three main functions of conservation, development and logical supports of education and research. In addition, traditional cultural values are preserved with the motto of UNESCO's "Man and Biosphere Program" (MAB program) with our principles: "Conservation for development and development for conservation". From a system viewpoint, each BR is a system of interrelated components; and a socio-ecology approach is aimed to clarify the interactions between ecosystems (natural) and social systems (human); the interactions all follow cause-and-effect principles; a cause may result in many effects and an effect may result from many causes; humans are a part of the 
ecosystem; and it is socio-ecology that expresses human ecology, and the relationship between men and nature (Ishwaran, Persic, \& Tri, 2008; Tri, 2005).

Learning society approach to analysis of possible implementation of education for sustainable development

Education for sustainable development launched by UNESCO, has been undertaken for a decade (2005-2014) with the aim to change the way we think and work in education, and approach learning society with innovative ways such as transformative learning and participatory learning; this will contribute to the great change in the society as well as of every individual. If each person experiences a lifelong learning process, the whole society will be a knowledge society that motivates the knowledge economy maintaining a sustainable future. Learning society approach covers learning activities extending beyond the formal education; They are not mutually exclusive but exist in harmony, combining learning activities with diversified forms for national and international sustainable development (Bottrill, 2016; McKeown, 2002). Methods of the study are based on system analysis and participatory interviews.

- System analysis method: System analysis is based on cause-effect flow diagrams with specialized softwares such as Vensim or Stella to demonstrate interactions between components in the system, and at the same time to find out "leverage" points - places to intervene in the system. The most commonly used method is the rapid rural appraisal (RRA and PRA) one in which there are deep interviews with respondents and open discussion between the interviewer and interviewee (respondents) (Y. Cavana, 2007).

- Participatory Interview: Within the framework of the study, questionnaires were designed and used to interview 177 households. Households were divided into two focus groups: commune officials and farmer households. This division assured the equal number of official households with opportunities for communication, exchange and learning from the media and farmer households with fewer of these opportunities.

It is shown in Table 1, the age and gender based analysis table, that the highest number of farmers and commune officials interviewed is aged 50-60 (32.7\%) and 30-40 (50.6\%) respectively (Fig. 4). With regard to gender, males account for the majority $(74.5 \%$ of farmers and $75.9 \%$ of village officials).

Table 1. Age and gender-based analysis of respondent households

\begin{tabular}{|c|c|c|c|c|}
\hline \multirow{2}{*}{ Age group and gender } & \multicolumn{2}{|c|}{ Farmers } & \multicolumn{2}{|c|}{ Commune officials } \\
\hline & No of respondents & $\%$ & No of respondents & $\%$ \\
\hline$<30$ & 7 & 7.1 & 17 & 21.5 \\
\hline $30-40$ & 21 & 21.4 & 40 & 50.6 \\
\hline $40-50$ & 30 & 30.6 & 15 & 19 \\
\hline $50-60$ & 32 & 32.7 & 7 & 8.9 \\
\hline$>60$ & 8 & 8.2 & 0 & 0 \\
\hline Female & 25 & 25.5 & 19 & 24.1 \\
\hline Male & 73 & 74.5 & 60 & 75.9 \\
\hline Total & 98 & 100 & 79 & 100 \\
\hline
\end{tabular}


In addition, the expert methodology was also employed for analysis of complex cases of historical factors, policies and directions.

\section{Results And Discussion}

\section{Biosphere reserve as a space for transformative learning (T-learning)}

In essence, the process of T-learning is a change of thinking. Like the changes in nature and society, they take place continuously in time and space. T-learning, by nature, belongs to adult education; this form of learning includes specific principles of learning tools which are empirical sensations/feelings based on the interpretation of cause-effect relationships, resulting in cognitive changes through critical thinking processes with new ideas in the transformation process (Mezirow, 1997).

Being zoned into three areas: core, buffer and transitional areas, each BR is required to show its landscape diversity, ecosystem diversity and species diversity representative of a bio-geographical region. This is the basis for the creation of spatial connections in nature, between nature and humans, and in humans, as shown in Fig. 1. During the field survey, it is also found that the geographic zoned space of the BR is the ideal place to conduct T-learning, with $31 \%$ of respondents agreeing to implement more forms of learning- the more the better. The combination of traditional forms with others such as oral communication (28\%), household-based and village-based learning (13\%) and local modelbased learning (learning by doing) (16\%) as seen in Fig. 2.

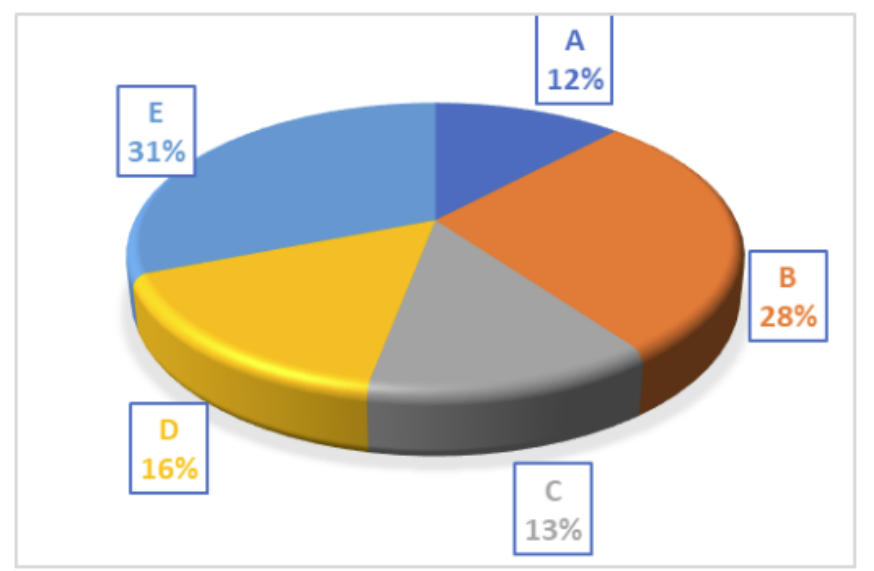
A: Theoretical learning at schools/classes without practical application;
B: Traditional oral learning/communication;
C: household meeting based learning in communes/villages;
D: Gathering of local people in a house where the host is a trainer;
E: All the above learning forms

Fig 2. Different forms of transformative learning in the community 


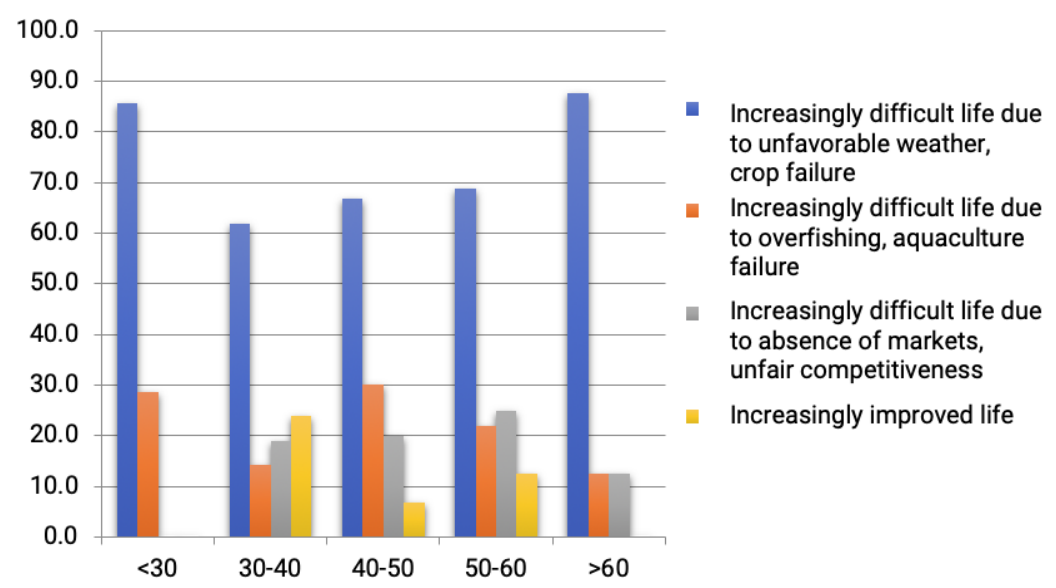

Fig 3. Community concerns about impacts of climate change on income of local people

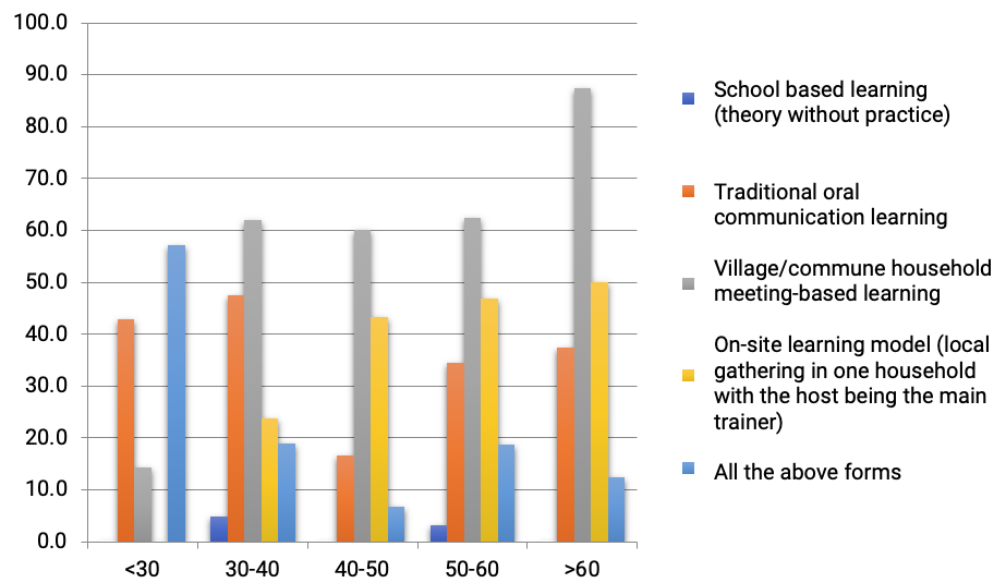

Fig 4. Different forms of learning favored by age groups

Therefore, a BR possesses a large geographical space covering various ecosystems, habitats and different types of labor/occupations would generate a diverse area for transformative learning activities. The results of the study also show that the implementation of the diverse learning forms is well in accordance with the requirements to perform functions of BRs. As such, a BR is an ideal tool for going through transformative learning processes; and it is T-learning process that facilitates the successful implementation of the functions of the BR.

The results of the survey on livelihood activities of the people (Table 2) show that most of the agricultural activities do not purely belong to a single sector/occupation; they are a combination of activities in agricultural field. This is consistent with the nature of the farm work, crop seasons and the characteristics of crop cultivation. Diversity of occupations and livelihoods create diverse learning needs, including resources, learning materials etc. Attention should be paid to diversity in space, forms, quality etc. during the implementation. Survey results reveal that most of age groups were engaged in agricultural activities; people aged 50-60 and over 60 occupied a large percentage (over $50 \%$ were involved in rice farming,wetland rice cultivation, subsidiary crop farming and nearly $40 \%$ in rice farming combined with 
aquaculture and fishing). People of these age groups witnesses great accumulated experiences - basic elements for Tlearning; they can be both trainers who are patient and sincere enough and trainees in community learning classes. It is natural, socio-economic and cultural conditions that generate favorable conditions for implementation of T-learning in BRs in general and Kien Giang BR in particular.

Table 2. Age and gender based agricultural activities of farmer households

\begin{tabular}{|c|c|c|c|c|c|c|c|c|}
\hline \multirow{2}{*}{ Agricultural activities } & \multicolumn{6}{|c|}{ Age group (\%) } & \multicolumn{2}{|c|}{ Gender (\%) } \\
\hline & $<30$ & $30-40$ & $40-50$ & $50-60$ & $>60$ & Total & Female & Male \\
\hline Rice farming, wetland rice cultivation, subsidiary crop farming & 28.6 & 19.0 & 30.0 & 46.9 & 50.0 & 34.7 & 44.0 & 31.5 \\
\hline Rice farming combined with aquaculture and fishing & 57.1 & 47.6 & 43.3 & 34.4 & 37.5 & 41.8 & 24.0 & 47.9 \\
\hline Rice farming combined with handicraft, small-scale trading, others (if any) & 14.3 & 19.0 & 0.0 & 0.0 & 0.0 & 5.1 & 0.0 & 6.8 \\
\hline Focus on aquaculture and fishing & 14.3 & 0.0 & 13.3 & 9.4 & 12.5 & 9.2 & 12.0 & 8.2 \\
\hline Focus on handicraft and small-scale trading & 14.3 & 14.3 & 20.0 & 3.1 & 0.0 & 11.2 & 16.0 & 9.6 \\
\hline Others & 14.3 & 9.5 & 6.7 & 15.6 & 0.0 & 10.2 & 16.0 & 8.2 \\
\hline
\end{tabular}

\section{Factors assuring the success of transformative learning processes (T-learning)}

Transformative learning processes require community involvement, employing new approaches, new methods and important factors: 1) learning needs that are the concerns of the community, 2) topics of concern and the mechanism for linking them (nexus), 3) finally, commitment of participants, as well as the use of transformative learning processes to address these concerns, including: 1) issues of concern and germ-cell models for T-learning, 2) Identify the stakeholders involved in these issues, 3) The scope and way of implementation of transformative learning processes, 4) Knowledge resources and ways of implementation 5) create learning networks by combining with formal, non-formal education.

Study findings also show the prioritized issues that need to be shared within the community, including Understanding of climate change and its impacts on agricultural activities (agriculture, forestry, fisheries). These are difficulties in local life reflected through the interactions between climate change and problems of food, water, energy and social equality (nexuses). It also involves with lessons learned from success and failures in adaptation measures for climate change, lessons learned in collaboration among and between stakeholders, and directions of state agencies and practical experience in disaster prevention of the local community.

Survey results of the community people at different ages show that most local people are concerned about increasing life difficulties due to unfavorable weather and crop failure. Only a few respondents said that life had been improved, indicating that the survey data much differed from those of the annual performance reports of the managers of different levels. Therefore, the conditions for successful implementation of T-learning should be based on actual survey data on community concerns. This is also an important factor in ensuring the successful implementation of transformative learning processes. 
In terms of learning forms, the highest percentage of respondents (27.2\%) supported the combination of all possible learning forms, while those in favor of the formal school-based learning accounted for $20.1 \%$; traditional oral communication learning saw the support of $11.5 \%$ of respondents and village/commune household meeting based learning 16.2\%; gathering-people-to-one-household model for on-site learning in which the main speaker is the host gained support of $25 \%$ respondents, which is the favorite form of learning of the locality. For most of these forms of learning, trainees are divided into groups; the exchanges within the group and between groups are the basic characteristics of community learning (shown in Fig 2).

Thus, T-learning not only provides a new approach to trainers and trainees but also creates a learning environment; this learning environment is not just a geographic space; it is a space of thought and the movement of thinking processes; this is where the topics of study are successful experiences or failures to be shared; this is the space of education derived from the real life.

As such, the first element to assure success of T-learning is to create a learning / educational space. It is the place for supporting ideas, sharing experiences and enriching the experience of individuals and communities. All personal issues (health, spirit, social relationships, thinking habits and lifestyle) lead to social freedom and justice. In relation to the field of education for sustainable development (ESD). It is based on ecological understanding in relationship with the role of an individual and his/her life experiences.

The type of group/teamwork learning is more supportive and also characteristic of the T-learning process. Learning in a team-work way is always accompanied by discussion and dialogues. Dialogues bring about the most effectiveness in Tlearning; dialogues are also the driving force to promote critical thinking before actions are taken, through which experiences are reflected, hypotheses, and beliefs are set and thinking habits are aroused. Although dialogues do not allow much time for analysis, they focus on the core issue as well as reliable and logical communication instead. The process of learning based on teamwork is the nursing of democratic life, psychotherapy, counseling psychology and social work.

Once communication is in a way of dialogue, one can listen and ask questions directly, expressing his/her opinions and concerns. It is the dialogue that gives the feeling of self-confidence and allows others to retain their opinions and open the heart to understand others without necessarily clarifying the opposition or objections in dialogue. It is important to identify a dialogue environment. To create this space, the necessary and sufficient conditions include:

- Participants in T-learning process need commitment and motivation; and team members need to respect the feedback of others. The working team provides an interpersonal/interaction space that is not always in place. Commitment and sharing in a warm space will facilitate learning from mystery, curiosity and openness to others.

- Curiosity and openness should be based on the belief that is considered to surely prepare for the "birth" of something new about others and about oneself.

- Emotional commitments are gained through experiences and stories that play a key role in creating these commitments. The connection usually occurs in the story-sharing process as we share our own stories. When we feel being heard and talk to some people as soul-mates, we have emotional feelings and increased connection with them.

- Reflection and two-way interaction are created when stories are told; feedbacks from members provide new details to the group that is of social sharing significance. Concerns and pressing problems are a catalyst for the group to think about the issue and propose solutions based on their views and experiences. 
- The basic characteristics of a T-learning space: 1 ) the learning process that occurs in the presence of relationships 2) it is these relationships that are shared and that in turn affect the learning space 3) serve as a room containing ideas, sensations, body, soul, and thinking 4) provide enough time for coordination, action, reflection and integration 5) facilitate a process with the questions, needs and goals of the learner.

As shown in Table 3 on community experience learned from projects and programs implemented in the locality, the process of transformative learning creates the demand for critical thinking in various aspects in order to take continued actions, to review and to have a dialogue in different forms. The dialogue usually begins with a story of one's experience, problem analysis or raising a problem to be solved, renaming a problem that needs change etc.

Table 3. Community experience learned from projects and programs implemented in the locality

\begin{tabular}{|c|c|c|c|c|c|c|c|c|}
\hline \multirow{2}{*}{$\begin{array}{l}\text { Action programs with support from the government/universities in response to climate } \\
\text { change }\end{array}$} & \multicolumn{6}{|c|}{ Age group (\%) } & \multicolumn{2}{|c|}{$\operatorname{Sex}(\%)$} \\
\hline & $<30$ & $30-40$ & $40-50$ & $50-60$ & $>60$ & Total & Female & Male \\
\hline \multirow{2}{*}{ Experiment with drought-tolerant plants } & 28.6 & 28.6 & 3.3 & 18.8 & 37.5 & 18.4 & 12.0 & 20.5 \\
\hline & 28.6 & 14.3 & 20.0 & 6.3 & 12.5 & 14.3 & 4.0 & 17.8 \\
\hline Mangrove planting in coastal areas & 28.6 & 28.6 & 30.0 & 18.8 & 25.0 & 25.5 & 32.0 & 23.3 \\
\hline Oyster/Meretrix farming combined with mangrove protection & 28.6 & 19.0 & 26.7 & 21.9 & 37.5 & 24.5 & 24.0 & 24.7 \\
\hline Community tourism combined with livelihood development & 0.0 & 9.5 & 0.0 & 0.0 & 0.0 & 2.0 & 0.0 & 2.7 \\
\hline Closed production model: Garden-Pond-Stall-Biogas & 0.0 & 9.5 & 6.7 & 15.6 & 12.5 & 10.2 & 24.0 & 5.5 \\
\hline Training of skills to respond to climate change & 0.0 & 14.3 & 26.7 & 21.9 & 12.5 & 19.4 & 16.0 & 20.5 \\
\hline Occupation training & 0.0 & 4.8 & 0.0 & 0.0 & 12.5 & 2.0 & 0.0 & 2.7 \\
\hline Others & 0.0 & 4.8 & 3.3 & 0.0 & 0.0 & 2.0 & 0.0 & 2.7 \\
\hline
\end{tabular}

The survey results show that most of the programs and projects focus on two isues of coastal mangroves planting and oyster/Meretrix farming combined with mangrove protection; one subject is afforestation and the other emphasizes the sustainable management of this system through the connection between restoration, conservation and improvement of livelihoods. This is really a great experience for local communities inside and outside the province.

It is solutions and initiatives of individuals and communities concerning the above subject that are shared in T-learning. Survey findings on innovative solutions to climate change focus on freshwater storing for production and consumption. The change of occupations and finding of new livelihoods also account for a large proportion. Establishing groups of households together involved in production or looking for livelihoods is also of great significance to these important initiatives. The community solutions and initiatives in response to climate change are presented in Table 4. 
Table 4. Survey findings of community solutions and initiatives in response to climate change

\begin{tabular}{|l|l|l|l|l|l|l|l|l|}
\hline \multirow{2}{*}{ Own solutions / initiatives of the community and families in response to climate change } & \multicolumn{3}{|c|}{ Age group (\%) } \\
\cline { 2 - 8 } & $<30$ & $30-40$ & $40-50$ & $50-60$ & $>60$ & Total & Female & Male \\
\hline Storing freshwater for production and consumption & 85.7 & 81.0 & 93.3 & 71.9 & 87.5 & 82.7 & 84.0 & 82.2 \\
\hline Water-saving production model & 14.3 & 14.3 & 30.0 & 9.4 & 37.5 & 19.4 & 12.0 & 21.9 \\
\hline Sustainable integrated production model & 28.6 & 9.5 & 23.3 & 12.5 & 0.0 & 15.3 & 4.0 & 19.2 \\
\hline Structural change of crops (select plants and animals adaptive to climate change) & 28.6 & 23.8 & 6.7 & 34.4 & 25.0 & 22.4 & 12.0 & 26.0 \\
\hline Change to new occupations or other activities to earn a stable income & 42.9 & 33.3 & 20.0 & 25.0 & 0.0 & 24.5 & 32.0 & 21.9 \\
\hline Join production groups or livelihood groups & 14.3 & 4.8 & 6.7 & 21.9 & 12.5 & 12.2 & 20.0 & 9.6 \\
\hline Others & 0.0 & 0.0 & 3.3 & 3.1 & 12.5 & 3.1 & 0.0 & 4.1 \\
\hline
\end{tabular}

\section{Conclusion}

T-learning is the core of the learning society model launched by UNESCO and several international organizations towards a sustainable future. The results of the study are evidences of the successful applicability of T-learning in Kien Giang WBR which acts as a geographic space, a space for thinking, thereby generating ideas and initiatives to be shared based on personal and community experiences. Therefore, the structure and function of the UNESCO / MAB-oriented Biosphere Reserve will facilitate the successful implementation of a T-learning model in particular and the promotion of a learning society in general. This would contribute to successfully achieving national and international sustainable development goals. In contrast, the implementation of a T-learning model in Kien Giang Biosphere Reserve would contribute to successful fulfilment of the tasks and functions of this Biosphere Reserve.

In order to successfully implement this model, the basic elements include: 1) the BR should have a good governance mechanism with the enthusiastic, responsible and well-qualified staff (from the province to grassroots' level) to create a large connection space as the basis for the connection between nature and nature, between human and nature and between human and human. 2) T-learning is needed by the community with both immediate and long-term concerns, the need to share both successful and unsuccessful experiences, based on the experiences of the trainees themselves; and then community members will be able to come up with appropriate action plans. 3) Teamwork learning through dialogues and discussion will facilitate the process of democratization that creates the motivation to change thinking and to actively innovate with the sense that global citizens make a positive transformation and finally, 4) The establishment and maintenance of a "germ cell" network with many experiences and willingness to share both successes and failures. Therefore, the experience of implementing the model of T-learning in Kien Giang Biosphere Reserve needs to be widely replicated, shared and discussed in national and international forums and conferences, contributing to the success of sustainable development at local, national and international levels. 


\section{Acknowledgements}

On behalf of the study members, we would like to express our sincere thanks and affirm that this is the output of the project of cooperation between Center for Environmental Research and Education (CERE), Center for Education Research and Support for Sustainable Development (CEREPROD), Hanoi National University of Education (HNUE) and Management Board for Kien Giang Biosphere Reserve, Department of Science and Technology of Kien Giang Province; the study project is under the financial support of the Transformative Knowledge Network Grant no: 160314115141.

\section{References}

Bottrill, C. (2016). How Transformative Education can Enrich Lives - Cross-Cultural Learning in Northern Vietnam.

Committee, K. G. P. (2006). Nomination form for Kien Giang Biosphere Reserve.

Cranton, P. (2016). Understanding and promoting transformative learning - Aguide to theory and practice. Stylus.

Edward W Taylor, P. C. (2012). The Handbook of Transformative Learning: Theory, Research, and Practice. [book]. 598.

Ha, T. M., Bosch, O. J., \& Nguyen, N. C. (2016). Practical Value of the Systems-based Evolutionary Learning Laboratory in Solving Complex Community Problems in Vietnam. Paper presented at the Proceedings of the 59th Annual Meeting of the ISSS-2015 Berlin, Germany.

Ishwaran, N., Persic, A., \& Tri, N. H. (2008). Concept and practice: the case of UNESCO biosphere reserves. International Journal of Environment and Sustainable Development, 7(2), 118-131.

Lotz-Sisitka, H., Ali, M. B., Mphepo, G., Chaves, M., Macintyre, T., Pesanayi, T., ... Tran, D. T. (2016). Co-designing research on transgressive learning in times of climate change. Current Opinion in Environmental Sustainability, 20, 50-55.

McKeown, R. (2002). Education for Sustainable Development Toolkit. UNESCO serie 2002 (version 2), 142.

Mezirow, J. (1997). Transformative learning: Theory to practice. New directions for adult and continuing education, $1997(74), 5-12$.

PC, K. G. (2014). Nomination form for proposed Kien Giang Biosphere Reserve. 240.

Tri, N. H. (2005). Biospheres and Biosphere Reserves. Hanoi National University of Education.

UNESCO/MAB. (2015). MAB Strategy 2015-2015. 18.

UNESCO/MAB. (2016). Lima Action Plan 2016-2025. 11.

Wals, A. E. (2009). Social learning towards a sustainable world: Principles, perspectives, and praxis: Wageningen Academic Pub.

Y. Cavana, K. E. M. R. (2007). System thinking, System dynamics - Managing change and complexity. 261. 